\section{Angulation change of the third molar tooth in orthodontic treatment}

\author{
Ardiansyah S. Pawinru*
}

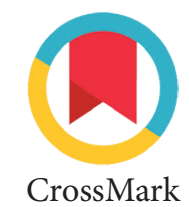

CrossMark

\title{
Abstract
}

Objective: Impaction of the third molar tooth mandibular is often found in patients with orthodontic treatment. In orthodontic treatment, extraction cases of impaction of the third molar tooth are usually performed but the patients often refuse this extraction. Extraction of premolar has a good effect on the third molar mandibular angulation during treatment.

Material and Methods: This study is a retrospective clinical study with descriptive analytic to find out the effect of the first mandibular premolar tooth extraction to angulation change of the third molar mandibular in orthodontic treatment with a standard edgewise method. Angulation change was performed by comparing the third molar mandibular angulation before and after orthodontic treatment with panoramic radiographs. Angulation of the third molar tooth mandibular was calculated from the angle formed between the long axis of the tooth with the reference line infra-orbital.

Results: The sample was divided into three (3) groups of patients before treatment angulation of the third molar tooth mandibular under $30^{\circ}, 30^{\circ}$ to $60^{\circ}$ and above $60^{\circ}$, then measured change of angulation and observed whether it increased, fixed or decreased. Results were analyzed by T- test and Wilcoxon testshowed that there was a significant change in angulation of the thirdmolar mandibular in orthodontic treatment with the first premolartooth mandibular extraction.

Conclusion: The first premolar tooth mandibular extraction affects the angulation of the third molar tooth mandibular after orthodontic treatment.
Department of Orthodontic, Faculty of Dentistry, Hasanuddin University, Makassar, Indonesia

*Correspondence to:

Ardiansyah S. Pawinru, Department of Orthodontic, Faculty of Dentistry, Hasanuddin University, Makassar, Indonesia pawinru190879@gmail.com

Received 15 December 2016 Revised 18 December 2016 Accepted 03 January 2017 Available online 01 April 2017
Keywords: Angulation, Mandibular third molar, First premolar tooth extraction

Cite this Article: Pawinru AS. 2017. Angulation change of the third molar tooth in orthodontic treatment. Journal of Dentomaxillofacial Science 2(1): 32-36. DOl:10.15562/jdmfs.v2i1.448

\section{Introduction}

Impaction tooth is tooth which fail to erupt completely at the right position. Impaction can happen because no space is available for tooth to grow in jaw and improper tooth angulation. Some cause factors are the bone is thick and compact, no space is available for tooth growth, next tooth obstructs tooth eruption, desidui tooth persistence and soft tissue cover chewy and rough tooth. Meanwhile, cause factors of the tooth itself are position and direction of tooth seed are abnormal, tooth eruption strength is less as well. ${ }^{1,2}$

Generally, in plan of patient orthodontic treatment with impaction case of third molar tooth of mandibular is by repealing the tooth but sometimes patient refuses, and that condition can affect plan, result and stability of orthodontic treatment as well. One factor that influences stability of orthodontic treatment is alignment of tooth root, therefore in order to get stabile treatment result needed good tooth angulation so that it can distribute occlusal force proportionally in every tooth contact including the third molar tooth. Position and angulation of the third molar tooth of mandibular that are mesioangular impaction will cause the tooth impulsion to anterior because of anterior component force that results to force distribution by stomatognacy system. ${ }^{2-4}$

In treatment of orthodontic with molar tooth impaction, there are three things that have to be considered whether it needs movement to the first molar tooth of distal or the second molar, or whether there is any space after extraction of other permanent teeth like premolar tooth when orthodontic treatment is performed. ${ }^{3,5}$

It have found that there is angulation construction of the third molar mandibular in orthodontic patient with tooth extraction of premolar mandibular, because of the first molar tooth movement and the second molar tooth to mesial give more space in retro-molar so that it is possible to cause angulation change in the third molar tooth of mandibular. Yetin the third molar tooth of mandibular which isslant more than 40 degrees mesial toward occlusal plain in the end of treatment causes rising of impac-tion risk. ${ }^{2,6}$

Angulation change of the third molar tooth of mandibular besides can be detected by clinical intra oral, teeth mold as well as radiographic, panoramic 
$\mathrm{X}$-ray image is also a method that is often used to collect information about tooth position before and after orthodontic treatment. ${ }^{7,8}$ The aim of this research is to know the effect of the first premolar tooth extraction toward angulation change and direction of angulation change of the third molar tooth mandibular after orthodontic treatment by edgewise standard method.

\section{Material and Methods}

This research is a retrospective clinical research that is descriptive analytic to observe effect of the first premolar tooth extraction toward angulation change of the third molar tooth of mandibular in orthodontic treatment Edgewise standard fixed by using panoramic X-ray image before and after treatment. The research was performed in clinic of Orthodontic Specialist, Faculty of Dentistry, Padjadjaran University in the span April 2013 - December 2013.

Tooth angulation measurement was performed by look at the angle that is formed between long axis inclination line of the third molar tooth of mandibular and horizontal reference line. Horizontal reference line that is used is line that is withdrawn from left and right infra-orbital called infra-orbital line. Infra-orbital point is the most inferior point fromorbital bone that can be observed by radiographicimage from zygomatic bone lateral direction..$^{8-10}$

Fixed orthodontic treatment patients who had been treated and avowed cure were recorded first, then 30 patients who fulfilled the criteria were taken as sample. Sample panoramic images before and after treatment were collected. After that the panoramic images were placed on tracing paper and continued with calculation of angulation change angle. The first calculation was measurement of angulation angle of the third molar tooth mandibular before treatment by withdrawing line from long axis of the third molar tooth mandibular of left and right toward infraorbital line and was performed angle calculation of the third molar tooth mandibular left and right after treatment.

To avoid mistake because of human factor, calculation of this angulation angle was performed three times in the interval minimum 3 days. Figure 1 angulation angle of the 60 third molar teeth mandibular before treatment was divided in three angulation angle range groups those were below $30^{\circ}, 30^{\circ}$ to $60^{\circ}$ and above $60^{\circ}$.

Furthermore, figure 2 angulation angle of the third molar mandibular was calculated after treatment and measured deviation of angulation change before and after orthodontic treatment. And then,

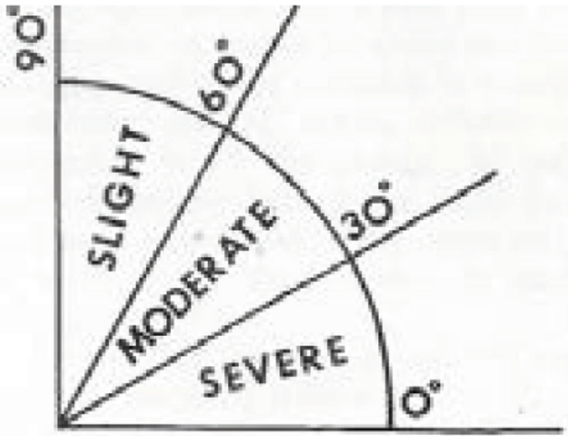

Figure 1 Classification of angulation of the third molar tooth mandibular group

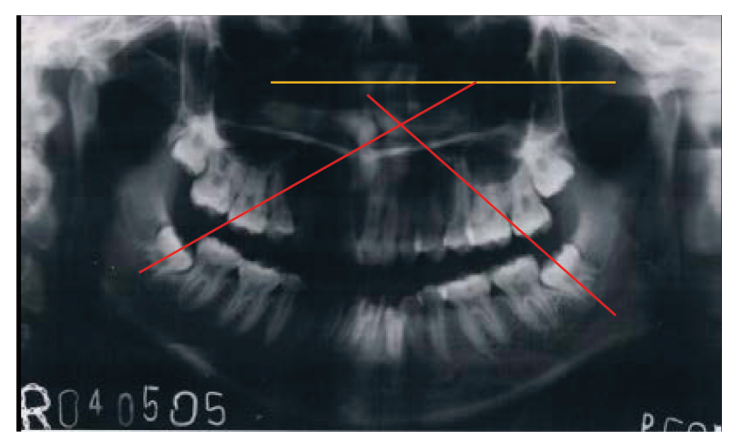

Figure 2 Angulation measurement of the third molar mandibular

Information: Infra-orbital line

The third molar tooth Angulation

the calculation result was analyzed statistically to perceive ratio of the third molar angulation change in orthodontic treatment by extraction of the first premolar mandibular.

\section{Results}

Measurement of angulation angle change of the third molar tooth mandibular was performed for the third molar tooth mandibular of left and right, so that total of the third molar tooth mandibular which were observed was 60 teeth from 30 patients who had been treated orthodontic with extraction case of the first premolar tooth mandibular consisted of 9 men and 21 women from 16 to 25 years old.

Based on table 1 and 2 above, angulation angle of the third molar tooth mandibular that experiences change consists of 36 teeth or $60 \%$ with smaller angulation angle and 24 teeth or $40 \%$ are bigger angulation angle after orthodontic treatment. By Wilcoxon test ratio angulation angle change bigger and smaller above, it is found that count value is $\mathrm{Z}-4.373$ with $\mathrm{p}$ value $=0.019$. This value is smaller than $\mathrm{p}$ value $<0.05$, so that the result is significant.

Based on table 3 above from 24 of the third mandibular molar tooth which experience wider 
Table 1 Angulation Change of The Third Molar Tooth Mandibular After Orthodontic Treatment

\begin{tabular}{|c|c|c|c|c|}
\hline & & $\mathbf{N}$ & $\%$ & Cum. \% \\
\hline$<$ & & 36 & 60 & 60 \\
\hline TB & & 0 & 0 & 60 \\
\hline$>$ & & 24 & 40 & 100 \\
\hline $\mathrm{N}$ & & 60 & 100.0 & \\
\hline Information: & $\begin{array}{c}\mathrm{n}=\text { Total } \\
\mathrm{TB}=\text { Fixed } \\
>=\text { Bigger }\end{array}$ & $\begin{array}{l}\mathrm{N} \\
< \\
\text { Cum. \% }\end{array}$ & $\begin{array}{l}=\text { Total } \\
=\text { Smaller } \\
=\text { Cumulative percentage }\end{array}$ & \\
\hline
\end{tabular}

Table 2 Wilcoxon Test, Ratio of Angle Change wider and narrower

\begin{tabular}{ll}
\hline & $>-<$ \\
\hline $\mathrm{Z}$ & -4.373 \\
Asymp. Sig. (2-tailed) & $0.019^{*}$
\end{tabular}

Information: p-value 0.05 .

$$
\begin{aligned}
& Z=\text { Count value } \\
& { }^{*}=\text { Significant }
\end{aligned}
$$

Table 3 Angulation Angle Change Frequency of The Third Molar Mandibular is wider After Orthodontic Treatment

\begin{tabular}{lcccc}
\hline & Freq & $\%$ & Val \% & Cum \% \\
\hline$<30$ & 9 & 37.5 & 37.5 & 37.5 \\
$30-60$ & 12 & 50 & 50 & 87.5 \\
$60<$ & 3 & 12.5 & 12.5 & 100.0 \\
$\mathrm{~N}$ & 24 & 100.0 & 100.0 & \\
\hline
\end{tabular}

Information: $<30=$ Angulation angle of the third molar tooth mandibular less than $30^{\circ}$ $30^{\circ}$ to $60^{\circ}=$ Angulation angle of the third molar tooth mandibular from $30^{\circ}$ to $60^{\circ}$ $60<=$ Angulation angle of the third molar tooth mandibular more than $60^{\circ}$ $\mathrm{N} \quad=$ Total sample

Table 4 Angulation angle change frequency of the third molar mandibular is narrower after orthodontic treatment

\begin{tabular}{lcccc}
\hline & Freq & $\%$ & Val \% & Cum \% \\
\hline$<30$ & 11 & 30.5 & 30.5 & 30.5 \\
$30-60$ & 18 & 50 & 50 & 80.5 \\
$60<$ & 7 & 19.5 & 19.5 & 100.0 \\
$\mathrm{~N}$ & 36 & 100.0 & 100.0 & \\
\hline
\end{tabular}

Information: $<30=$ Angulation angle of the third molar tooth mandibular less than $30^{\circ}$ $30^{\circ}$ to $60^{\circ}=$ Angulation angle of the third molar tooth mandibular from $30^{\circ}$ to $60^{\circ}$

$60<\quad=$ Angulation angle of the third molar tooth mandibular more than $60^{\circ}$

$\mathrm{N} \quad=$ Total sample

changing angulation divided into based on the initial angle of the angulation of the third mandibular molar which produces as follows: angulation angle of the third mandibular molar tooth less than $30^{\circ}$ as many as 9 teeth or $37.5 \%$, angulated angle between $30^{\circ}$ and $60^{\circ}$ as many as 12 teeth or $50 \%$ and angulated angle more than 60 as many as 3 teeth or $12.5 \%$.

Based on table 4 above of 36 the third mandib ular molar which conduct smaller angulation angle changing divided into the initial angle of the
Table 5 Angulation angle change frequency of the third molar mandibular is greater after orthodontic treatment

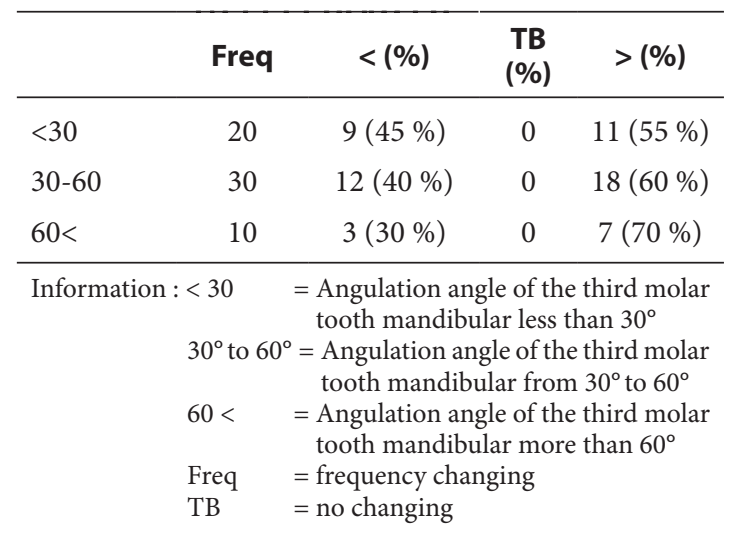

Table 6 Angle changing comparatives of the third molar mandibular on left

\begin{tabular}{|c|c|c|c|}
\hline & & n (\%) ka & n (\%) ki \\
\hline \multirow[t]{2}{*}{$<$} & & $21(70 \%)$ & $15(50 \%)$ \\
\hline & TB & $0(0 \%)$ & $0(0 \%)$ \\
\hline \multirow[t]{2}{*}{$>$} & & $9(30 \%)$ & $15(50 \%)$ \\
\hline & $\mathrm{N}$ & 30 & 30 \\
\hline & & $\begin{array}{l}\text { Less than } \\
\text { More than } \\
\text { number }\end{array}$ & $\begin{array}{l}\mathrm{TB}=\text { No changing } \\
\mathrm{N}=\text { Total }\end{array}$ \\
\hline
\end{tabular}
and right

third mandibular molar which resulted as follows angulation angle of the third mandibular molar tooth less than $30^{\circ}$ as many as 11 teeth or $30.5 \%$, angulated angle between $30^{\circ}$ and $60^{\circ}$ as many as 18 teeth or $50 \%$ and angulated angle more than $60^{\circ}$ as many as 7 teeth or $19.5 \%$.

Based on table 5 above, it indicates that the angulation angle changing of the third molar before treatment which less than $30^{\circ}$ of 20 teeth angulated angle changing become wider as many as 9 teeth of $45 \%$ and become narrower as many as 11 teeth or $55 \%$. In the third molar between $30^{\circ}$ and $60^{\circ}$ of angulated angle as many as $30^{\circ}$ teeth experience angulated changing as many as 12 teeth or $40 \%$ and more narrower as many as 18 or $60 \%$. The third molar teeth with angulation angle is more than $60^{\circ}$ as many as 10 teeth conduct a wider changing as many as 3 teeth or $30 \%$ and narrower as many as 7 teeth or $70 \%$.

Based on the table 6 above, of 30 molar teeth experience angulation change become narrower as many as 15 teeth or $50 \%$ and become wider as many as 15 teeth or $50 \%$, meanwhile 30 right region teeth, of which 21 teeth or $70 \%$ experience angulation change of the third mandibular molar teeth become narrower and 9 teeth or 30\% experience angulation change of the third mandibular molar become wider. 
Table 7 Mann-Whitney test on angular angle of the third molar mandibular teeth are wider and narrower on the left and right

\begin{tabular}{lcc}
\hline & $\mathbf{Z}$ & p-Value \\
\hline$>$ & -.209 & $.861^{\circ)}$ \\
$<$ & -.289 & $.776^{\circ}$ \\
\hline
\end{tabular}

Information : $\mathrm{P}<0.05$

$\left.{ }^{\circ}\right)$ : insignificant

$<)$ : narrower

$\mathrm{Z}$ : counting number

$>$ : wider
The other research reported in his study that the premolar teeth extraction in orthodontic treatment results to the changing of the third molar teeth horizontally as well as vertically. In contrast with the other found that the first premolar teeth loss in the orthodontic treatment with the third mandibular molar teeth in angulation less than 40 tend to change its angulation become narrower and risk on the further impaction. Different from researcher who found that the extraction of the first premolar teeth result in the increasing of the third angular molar teeth degree to the oclusal plane and may reduce impactial risk . 2,6,13

Statistical test describes that the angular changing of the third mandibular molar teeth in left and right region have no significant difference. It found that premolar teeth extraction influences angular changing of the third mandibular molar teeth both unilateral and bilateral impaction and have found that angulation change value of the third mandibular molar teeth after orthodontic treatment is unpredictable. ${ }^{3,14}$ of extraction and unextraction of the first premolar teeth in an orthodontic treatment to the angular changing of the third molar found that loss of the first premolar teeth provided a satisfied influence to the angular changing of the third mandibular molar teeth after treatment. found that by losing premolar teeth impacts posterior teeth movement to mesial direction thus provide a space in retro-molar and possibly result in angular changing of the third mandibular molar teeth 1 .

Some study reported that there are significant angular changing of the third mandibular molar teeth into group of loss of the first premolar teeth compare to the group of unextracted of the first premolar teeth. Angular changing of the third mandibular molar teeth occur may be influenced by the available space in the retromolar because of the movement to the mesial direction of the first molar teeth and the second molar teeth to fulfill available space because of the extraction. ${ }^{12}$

Wilcoxon test conducted to determine the angular changing differences of the third mandibular molar teeth between narrower and wider showing significant value of $\mathrm{P}=0.0019$, $\mathrm{p}$-value less than 0.05 table 2 . The result describes that angular changing of the third mandibular molar teeth in an orthodontic treatment of Edgewise standard method with the extraction of the first premolar teeth significantly results to a narrower angular changing compare to wider angular changing.

\section{Conclusion}

Angular changing of the third mandibular molar teeth become narrower in all teeth angle of the third mandibular molar teeth which impacted in the orthodontic treatment edgewise standard with the first mandibular premolar teeth extraction. Furthermore, in case of the third mandibular molar teeth impaction with the first mandibular premolar teeth loss, orthodontist should consider to perform tooth extraction for the third molar tooth.

\section{Conflict of Interest}

The authors report no conflict of interest.

\section{References}

1. Saysel MY, Gokce DM, Iiken K, et al. The effects of first Premolar extraction on third Molar angulations. Angle Orthod 2005;75: 719-722.

2. Artun J, Thalib L, Little RM. Third Molar angulation during and after treatment of adolescent Orthodontic patients. Eur J Orthod 2005;27: 590-596.

3. Alkuwari HM, Talaket AA, Alsahli RM, et al. Influence of orthodontic treatment with first Premolar extraction on the angulation of the Mandibular third Molar. Saudi Med J 2013;34: 639-643.

4. Tarazona B, Vanessa P, Jose M, et al. Influence of first and second Premolar extraction or non-extraction treatments on Mandibular third Molar angulation and position. A comparative study. Med Oral Patol Oral Cir Bucal 2010;15: 760-766.

5. Capelli J. Mandibular growth and third Molar impaction in extraction cases. Angle Orthod 1991;61: 223-229. 
6. Behbeni F, Artun J, Thalib L. Predicting of Mandibular third Molar impaction in adolescent Orthodontic patients. Am J Orthod Dentofac Orthop 2006;130: 47-55.

7. Ursi W, Almeida RR, Tavano O, et al. Assasessment Of Mesiodistal axial inclination through panoramic radiography. J Clin orthod 1990;24: 166-173.

8. McKee IW, Williamson PC, Lam EW. The accuracy of 4 panoramic unit in the projection of Mesiodistal tooth angulation. Am J Orthod Dentofac Orthop 2002;121: 166-175.

9. Gohilot A, Pradhan T, Keluskar KM. Effect first Premolar extraction on maxillary and Mandibular third Molar angulation after Orthodontic therapy. J Oral Biol Craniofac Res 2012;2: 97-104.

10. McMinn R, Hutchinggs R, Logan BM. Color atlas of head and neck anatomy. 2nd ed. Barcelona: Mosby wolf; 1994. p. 10-16.
11. Dierkes DD. An investigation of the Mandibular third Molars in Orthodontic cases. Angle Orthod 1975;45: 207-212.

12. Ke HF, Wang CL, Liu L, et al. Effects of first Premolar extractions on third Molar angulations. Shanghai Kou Qiang Yi Xue 2006;24: 228-230.

13. Guo XH, Qian YF, Feng QP. Effects of different Premolar extraction on lower third Molar eruption. Shanghai Kou Qiang Yi Xue 2007;16: 370-373.

14. Risse G. The Angulation of Uppert 1st Permanent Molars, The Key to Functional Occlusin. J Comp Dentof Orthod \& Orthop 2004;1: 20-32.

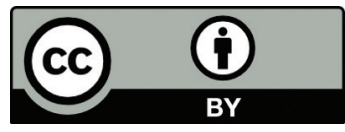

This work is licensed under a Creative Commons Attribution 